\title{
Elevated serum triglyceride predicts recurrence of colorectal polyps in patients with advanced adenomas
}

\author{
Boying Liu', Pingwu Wen ${ }^{1}$, Xiaodong $\mathrm{Gu}^{2}$, Ruiqiang Weng ${ }^{2}$ and Sudong Liu ${ }^{2,3^{*}}$ (D)
}

\begin{abstract}
Background: Recurrence of colorectal polyps is common and impacted by various factors. This study was performed to explore the association between lipid profiles and recurrence of colorectal polyps.

Methods: This study retrospectively analyzed the lipid profiles of 435 patients who underwent colonoscopy with removal of colorectal polyps and assessed recurrence of polyps by follow-up colonoscopy. Multivariate regression logistic analysis was used to evaluate the association between lipid profiles and polyp recurrence.

Results: During the 1.5-year follow-up, recurrence of colorectal polyps was observed in 135 of 435 patients (30.34\%). Patients with recurrent polyps showed a higher level of triglycerides $(P=0.006)$ and lower levels of highdensity lipoprotein cholesterol $(P=0.008)$ and apolipoprotein $\mathrm{A} 1(P=0.033)$. The multivariate regression logistic model suggested that an elevated triglyceride level was an independent risk factor for polyp recurrence (odds ratio, 1.55; $95 \%$ confidence interval, $1.02-2.35 ; P=0.039$ ) in patients with advanced adenoma.

Conclusions: Lipid profiles are associated with recurrence of colorectal polyps. An elevated triglyceride level is an independent risk predictor of polyp recurrence in patients with advanced adenoma.
\end{abstract}

Keywords: Colorectal polyp, Recurrence, Lipid profile, Triglyceride, Risk factor

\section{Introduction}

Colorectal cancer (CRC) is the second and third most common cancer in women and men, respectively, worldwide. It is also the fourth most deadly cancer worldwide [1]. In total, 1.8 million persons were reportedly diagnosed with CRC in 2018, resulting in the death of about 881,000 of these patients [2]. Endoscopic resection of colorectal polyps has effectively reduced the CRC-related mortality rate [3]. However, recurrence is common and remains a

\footnotetext{
* Correspondence: vanguard_1987@163.com

${ }^{2}$ Research Experimental Center, Meizhou People's Hospital (Huangtang Hospital), Meizhou Hospital Affiliated to Sun Yat-sen University, No. 63 Huangtang Road, Meijiang District, Meizhou 514031, P. R. China ${ }^{3}$ Guangdong Provincial Key Laboratory of Precision Medicine and Clinical Translational Research of Hakka Population, No. 63 Huangtang Road, Meijiang District, Meizhou 514031, P. R. China

Full list of author information is available at the end of the article
}

major concern for patients after resection [4-6]. Therefore, identification of risk factors associated with polyp recurrence is needed to improve the outcomes of patients with polyps and reduce the incidence of CRC.

CRC is known to develop from colorectal polyps, which are lesions that grow on the mucosal surface and protrude into the colorectal lumen [7]. According to the World Health Organization, colorectal polyps are divided into four types: adenomatous, inflammatory, hyperplastic, and hamartomic polyps [8]. The occurrence rates of different types of polyps widely range from 1 to $43 \%$ [6]. Specific factors have been reported to contribute to polyp recurrence, such as age, sex, lifestyle, and polyp characteristics [9]. Obesity and the body mass index (BMI) have long been studied as risk factors for polyp recurrence [10-12]. Researchers have found that 
obesity promotes the expression of insulin and insulinlike growth factor-1 (IGF-1), causing the transformation of non-advanced colorectal polyps to advanced polyps and triggering recurrence [13]. Several recent studies have shown that metabolic syndrome is associated with an increased risk of recurrent colorectal adenoma [14, 15]. Metabolic factors (age, BMI, and fasting blood glucose) significantly accelerate the development of recurrence after removal of adenomas [15].

The relationship between lipid profiles and colorectal polyps has been extensively studied. Some studies have shown that the serum triglyceride (TG) and cholesterol levels are associated with an increased risk of colorectal adenoma [16, 17], while other studies have failed to confirm such a link or have suggested an inverse relationship between serum lipid levels and colorectal adenoma $[18,19]$. A recent study revealed that increased serum TG and low-density lipoprotein cholesterol (LDL-C) levels promote the formation of colorectal polyps [20]. The underlying mechanisms have not yet been fully elucidated, but two pathways might be involved. One suggests that lipid abnormalities are involved in the development of hyperinsulinemia and insulin resistance, which inhibit apoptosis by interacting with the IGF-1 receptor, promote proliferation of large bowel cells, and induce carcinogenesis [21]. Second, lipid abnormalities might be associated with the production of bile acids, which have been proven to increase the risk of CRC [22]. It is reasonable to anticipate that serum lipids play a role in polyp recurrence. However, the relationship between serum lipid levels and polyp recurrence remains poorly understood.

In the current study, baseline lipid profiles as well as other baseline parameters were compared between patients with recurrent and non-recurrent polyps. The aim of this study was to evaluate the relationship between serum lipid profiles and polyp recurrence and identify potential markers that can be used to predict polyp recurrence.

\section{Materials and methods}

\section{Participants}

The participants of this retrospective study were selected from patients in the Endoscopic Center of the Gastroenterology Department at Meizhou People's Hospital who underwent complete colonoscopy and first-time removal of colorectal polyps from January 2018 to June 2019. The inclusion criteria were a histological diagnosis of colorectal polyps, at least one follow-up colonoscopy performed at more than 6 months later after polyp removal, and sufficient baseline clinical and laboratory data. Patients were excluded if they had present/previous gastrointestinal tumors or cardiac or pulmonary disease. The study was approved by the Ethics Committee of
Meizhou People's Hospital Affiliated to Sun Yat-Sen University.

A total of 3980 patients underwent an initial colonoscopy examination and removal of colorectal polyps during the study period. Of these 3980 patients, 3207 were excluded because they did not undergo follow-up colonoscopy. Of the remaining 773 patients, 314 lacked follow-up colonoscopy data $>6$ months after removal and 24 lacked baseline lipid data. Finally, 435 patients were included in the analysis (Fig. 1).

\section{Colonoscopy procedure}

Patients were required to consume a liquid diet for $24 \mathrm{~h}$ before the examination, and polyethylene glycol was used for standard bowel preparation. A complete colonoscopy including a good bowel preparation, colonoscopy reaching the cecum, and removing visualized lesions by endoscopic mucosal resection (EMR) was performed by experienced physicians. Biopsy specimens were inspected under a microscope by experienced pathologists.

\section{Polyp classification and definition of polyp recurrence} The pathologic characteristics of the colorectal polyps were obtained from the patients' pathology reports. The polyps were classified into hyperplastic polyps, inflammatory polyps, tubular adenoma, or tubulovillous adenoma. Advanced polyps were diagnosed if one or more of the following conditions were met: tubular adenoma of $\geq 10 \mathrm{~mm}$ in diameter, tubulovillous adenoma, or the presence of high-grade dysplasia [23]. The location of the polyps was defined as proximal (cecum, ascending colon, hepatic flexure, transverse colon, and splenic flexure) or distal (descending colon, sigmoid colon, and rectum). In patients with multiple polyps, the histologic type, size, and location was based on the largest and/or most advanced adenoma.

Polyp recurrence was defined as the discovery of any polyp in the follow-up colonoscopy examination performed at least 6 months after the initial removal, whether at the same location or at other locations [12, 24].

\section{Lipid profile testing and clinical data collection}

Peripheral venous blood samples were collected within $24 \mathrm{~h}$ after admission. The fasting lipid profiles, including the levels of total cholesterol, TG, high-density lipoprotein cholesterol (HDL-C), and LDL-C, were examined by selective solubilization (AU5800 analyzer; Beckman Coulter, Brea, CA, USA). The apolipoprotein A1 (ApoA1) and apolipoprotein B (ApoB) levels were tested using standard turbidimetric immunoassays (AU5800 analyzer; Beckman Coulter). Baseline characteristics including sex, age, BMI, drinking/smoking history, hypertension, and diabetes mellitus were collected from the medical records. 
Patients underwent removal of polyps

during Jan. 2018 to June $2019(n=3,980)$

Excluded:1.no surveillance colonoscopy $(n=3,147)$

2. no pathology data $(n=60)$

Patients with follow-up colonoscopy $(n=773)$

Excluded:1. follow-up colonoscopy $<6$ months $(n=314)$

2. without lipid data at baseline $(n=24)$

Patients eligible for analysis $(n=435)$

Fig. 1 Inclusion and exclusion criteria of the study participants

Drinking was defined as positive when alcohol consumption amounted to $>30 \mathrm{~g} /$ day. Hypertension was defined as blood pressure of $\geq 130 / 85 \mathrm{mmHg}$ and/or current use of antihypertensive medication. Diabetes mellitus was diagnosed if the patient had a fasting blood glucose level of $\geq 126 \mathrm{mg} / \mathrm{dL}$, a random glucose level of $\geq 200 \mathrm{mg} / \mathrm{dL}$, or was taking an antidiabetic medication [25]. Dyslipidemia was defined as a total cholesterol level of $\geq 5.17 \mathrm{mmol} / \mathrm{L}$, TG level of $\geq 1.7 \mathrm{mmol} / \mathrm{L}$, HDL-C level of $<1.04 \mathrm{mmol} / \mathrm{L}$, LDL-C level of $\geq 4.14 \mathrm{mmol} / \mathrm{L}$, or current treatment with antidyslipidemic medication.

\section{Statistical analysis}

Statistical analyses were performed using SPSS software version 22.0 (IBM Corp., Armonk, NY, USA). Continuous variables are expressed as mean \pm standard deviation, and categorical variables are expressed as proportion. The normality of the distribution of continuous variables was evaluated with the Kolmogorov-Smirnov test. Continuous variables were tested by Student's t test, whereas categorical variables were analyzed by the chi-square $\left(\chi^{2}\right)$ test or Fisher's exact test. Bonferroni correction was used for multiple comparisons. Logistic regression analysis was used to investigate the association of serum lipids and polyp recurrence. Odds ratios (ORs) were calculated by adjusting for variables that were distributed differently between patients with and without recurrence. All tests were two-sided, and a $P$ value of $<0.05$ was considered statistically significant.

\section{Results}

\section{Patients' baseline characteristics}

In total, 435 patients were analyzed in the present study. Each patient completed a follow-up of at least 1.5 years unless found to have recurrent polyps by colonoscopy. The baseline characteristics of the 435 patients are presented in Table 1. The patients' mean age was $56.6 \pm$ 10.7 years. Male patients (56.3\%) slightly outnumbered female patients. Few patients had a drinking habit (2.8\%) or smoking habit $(11.0 \%)$. The proportions of patients with hypertension, diabetes mellitus, and dyslipidemia were 19.1, 6.9, and 26.9\%, respectively.

During the 1.5-year follow-up, polyp recurrence was found in 132 patients (30.3\%). Patients with recurrent polyps were older than those without recurrent polyps $(P<0.008)$ and comprised a higher proportion of male patients $(P<0.001)$. Patients with recurrent polyps had a higher TG level $(P=0.006)$ and lower HDL-C and ApoA1 levels $(P=0.008$ and 0.033 , respectively). The TG to HDL ratio (TG/HDL) was significantly higher in patients with than without recurrent polyps $(P=0.006)$.

\section{Comparison of polyp characteristics between patients with and without recurrence}

The characteristics of the removed polyps are presented in Table 2. Most polyps (74.94\%) had a diameter of $\leq 10$ $\mathrm{mm}$. Large polyps $(\geq 20 \mathrm{~mm})$ were significantly more frequent in patients with than without recurrence ( $16.67 \%$ vs. $8.25 \%$, respectively; $P=0.036$ ). The number of polyps was significantly different between patients 
Table 1 Baseline characteristics of the study participants

\begin{tabular}{|c|c|c|c|c|}
\hline Parameter & $\begin{array}{l}\text { Total } \\
(n=435)\end{array}$ & $\begin{array}{l}\text { Recurrent } \\
(n=132)\end{array}$ & $\begin{array}{l}\text { Nonrecurrent } \\
(n=303)\end{array}$ & $P$-value \\
\hline Age (years) & $56.6 \pm 10.7$ & $58.6 \pm 9.7$ & $55.7 \pm 10.9$ & 0.008 \\
\hline Male (n, \%) & $245(56.3 \%)$ & $92(69.7 \%)$ & $153(50.5 \%)$ & $<0.001$ \\
\hline Follow-up (month) & $10.8 \pm 4.5$ & $11.7 \pm 5.0$ & $10.4 \pm 4.2$ & 0.003 \\
\hline $\mathrm{BMI}\left(\mathrm{kg} / \mathrm{m}^{2}\right)$ & $23.2 \pm 3.3$ & $22.9 \pm 3.2$ & $24.0 \pm 3.5$ & 0.003 \\
\hline Drink (n, \%) & $12(2.8 \%)$ & $8(6.1 \%)$ & $4(1.32 \%)$ & 0.009 \\
\hline Smoke (n, \%) & $48(11.0 \%)$ & 18(13.6\%) & $30(9.9 \%)$ & 0.249 \\
\hline Hypertension (n, \%) & 83(19.1\%) & $29(22.0 \%)$ & $54(17.2 \%)$ & 0.353 \\
\hline Diabetes Mellitus (n, \%) & $30(6.9 \%)$ & $9(6.8 \%)$ & $21(6.9 \%)$ & 1.00 \\
\hline Dyslipidemia (n, \%) & $117(26.9 \%)$ & $42(31.8 \%)$ & $75(24.8 \%)$ & 0.127 \\
\hline TC $(\mathrm{mmol} / \mathrm{L})$ & $5.49 \pm 1.22$ & $5.44 \pm 1.23$ & $5.40 \pm 1.14$ & 0.727 \\
\hline TG $(\mathrm{mmol} / \mathrm{L})$ & $1.72 \pm 1.15$ & $1.74 \pm 1.24$ & $1.44 \pm 0.92$ & 0.006 \\
\hline $\mathrm{HDL}-\mathrm{C}(\mathrm{mmol} / \mathrm{L})$ & $1.35 \pm 0.33$ & $1.32 \pm 0.33$ & $1.42 \pm 0.38$ & 0.008 \\
\hline LDL-C (mmol/L) & $3.21 \pm 0.85$ & $3.12 \pm 0.85$ & $3.08 \pm 0.83$ & 0.646 \\
\hline ApoA1(g/L) & $1.29 \pm 0.33$ & $1.28 \pm 0.33$ & $1.37 \pm 0.40$ & 0.033 \\
\hline $\mathrm{ApoB}(\mathrm{g} / \mathrm{L})$ & $1.02 \pm 0.28$ & $0.97 \pm 0.28$ & $0.96 \pm 0.28$ & 0.653 \\
\hline TG/HDL & $1.47 \pm 1.24$ & $1.48 \pm 1.37$ & $1.16 \pm 1.00$ & 0.006 \\
\hline
\end{tabular}

$B M I$ body mass index, TC total cholesterol, TG triglycerides, HDL-C high-density lipoprotein cholesterol, LDL-C low-density lipoprotein cholesterol, ApoA1 apoliprotein A1, ApoB apoliprotein B

$P$-value: Comparison between recurrent and nonrecurrent performed by Student's t test or Chi-square $\left(X^{2}\right)$ test

Table 2 Comparison of colorectal polyps between patients with and without polyp recurrence

\begin{tabular}{|c|c|c|c|c|c|}
\hline Parameter & $\begin{array}{l}\text { Total } \\
(n=435)\end{array}$ & $\begin{array}{l}\text { Recurrent } \\
(n=132)\end{array}$ & $\begin{array}{l}\text { Nonrecurrent } \\
(n=303)\end{array}$ & $\begin{array}{l}P \\
\text {-value }\end{array}$ & $P$-value \\
\hline Polyp size $(\mathrm{mm})$ & & & & 0.019 & \\
\hline$\leq 10$ & $326(74.94 \%)$ & $96(72.73 \%)$ & $230(75.91 \%)$ & 0.482 & \\
\hline $10-19$ & $62(14.25 \%)$ & $14(10.61 \%)$ & 48(15.84\%) & 0.151 & \\
\hline$\geq 20$ & 47 (10.80\%) & $22(16.67 \%)$ & $25(8.25 \%)$ & 0.012 & 0.036 \\
\hline Polyp number, n (\%) & & & & $<0.001$ & \\
\hline 1 & 139(31.95\%) & $20(15.15 \%)$ & $119(39.27 \%)$ & $<0.001$ & $<0.001$ \\
\hline 2 & $101(23.22 \%)$ & $24(18.18 \%)$ & $77(25.41 \%)$ & 0.097 & \\
\hline$\geq 3$ & 194(44.60\%) & $88(66.67 \%)$ & $106(34.98 \%)$ & $<0.001$ & $<0.001$ \\
\hline Polyp type, n (\%) & & & & 0.028 & \\
\hline Hyperplastic & $53(12.18 \%)$ & $17(12.88 \%)$ & $36(11.88 \%)$ & 0.770 & \\
\hline Inflammatory & $33(7.59 \%)$ & 7(5.30\%) & $26(8.58 \%)$ & 0.425 & \\
\hline Tubular adenoma & $285(62.52 \%)$ & $79(59.85 \%)$ & 206(67.99\%) & 0.101 & \\
\hline Tubulovillous adenoma & 64(14.71\%) & $29(21.97 \%)$ & $35(11.55 \%)$ & 0.005 & 0.02 \\
\hline Polyp location, n (\%) & & & & 0.149 & \\
\hline Proximal & 137(31.50\%) & $48(36.36 \%)$ & $89(29.37 \%)$ & & \\
\hline Dismal & $298(68.50 \%)$ & $84(63.64 \%)$ & $214(70.63 \%)$ & & \\
\hline Adenoma, n (\%) & & & & 0.116 & \\
\hline Advanced & $150(42.86 \%)$ & $53(49.07 \%)$ & $97(40.08 \%)$ & & \\
\hline Nonadvanced & $200(57.14 \%)$ & $55(50.93 \%)$ & $145(59.92 \%)$ & & \\
\hline
\end{tabular}

$P$-value: Comparison between recurrent and nonrecurrent performed by Chi-square $x^{2}$ test $P$-value ${ }^{\#}: P$ value after Bonferroni correction for multiple comparisons 
with and without recurrence $(P<0.001)$. Patients with recurrence had a significantly higher proportion of multiple polyps $(\geq 3)$ than those without recurrence $(66.67 \%$ vs. $34.98 \%$, respectively; $P<0.001)$. The histology of the polyps was different between patients with and without recurrence $(P=0.028)$, with a higher rate of tubulovillous adenoma found in patients with than without recurrence $(21.97 \%$ vs. $11.55 \%$, respectively; $P=0.02)$. The polyp locations and adenoma classifications were not significantly different between patients with and without recurrence.

\section{Comparison of serum lipid profiles between patients with and without polyp recurrence}

The serum lipid levels were analyzed in patients with different colorectal polyps. Among patients with hyperplastic polyps, those with recurrence had a higher TG level and TG/HDL $(P<0.05)$. Among patients with tubulovillous adenomas, those with recurrence had a higher TG level and TG/HDL $(P<0.05)$ and lower HDL and ApoA1 levels $(P<0.05)$. Among patients with inflammatory polyps or tubular adenomas, those with recurrence had a higher TG level and TG/HDL; however, the difference did not reach statistical significance. The LDL-C level tended to be high in all patient groups, but the differences were not statistically significant among the four polyp groups (Table 3 ).

\section{Association of elevated TG level with recurrence of colorectal polyps}

Regression logistic analysis was used to determine the risk factors associated with polyp recurrence. As shown in Table 4, among patients with overall polyps, male sex [OR, 1.75; 95\% confidence interval (CI), 1.06-2.89], the number of polyps (OR, 3.42; 95\% CI, 2.15-5.45) and the BMI (OR, 1.11; 95\% CI, 1.02-1.19) significantly increased the risk of polyp recurrence. Among patients with advanced adenoma, the number of polyps (OR, 3.28; 95\% CI, 1.44-7.47), the polyp size (OR, 2.86; $95 \%$ CI, 1.24-6.61), and the elevated TG level (OR, 1.55; 95\%
CI, 1.02-2.35) remained significant predictors of polyp recurrence.

\section{Discussion}

Recurrence of colorectal polyps is common and remains a crucial problem in the prevention of CRC. Although several factors have been revealed to impact the recurrence rate, few studies have focused on the role of the lipid profile. The present study analyzed the baseline lipid profiles of patients with colorectal polyps and the recurrence of polyps with a modest follow-up duration. The data showed that patients with recurrence had a higher TG level and lower HDL-C and ApoA1 levels than those without recurrence. To the best of our knowledge, this is the first study to demonstrate that an elevated TG level significantly predicts polyp recurrence in patients with advanced adenoma.

Colorectal polyps are precursors of CRC, and removal of polyps effectively reduces the risk of developing CRC. Endoscopic resection is now widely used to excise colorectal polyps and thus reduces the incidence of death caused by CRC [3]. However, the high recurrence rate after piecemeal resection poses a serious clinical problem. One clinical trial showed that 20 to $50 \%$ of patients with colorectal adenomas developed recurrence within a 3- to 5-year period [26]. During the short-term followup in the present study, we observed polyp recurrence in 132 of 435 patients (30.34\%). Elucidation of the causative factors of polyp recurrence may practically reduce or delay the recurrence of polyps.

Several factors are reportedly associated with polyp recurrence, including age, sex, lifestyle, genetic background, polyp characteristics, and procedural factors [9, 27-30]. The present study compared the baseline clinical characteristics of both the patients and the colorectal polyps. In accordance with previous studies, significant differences were observed in age, sex, polyp size, and polyp number between patients with and without polyp recurrence. The proportion of people with obesity in the general population has sharply increased, and obesity causes or aggravates disease. Epidemiologic

Table 3 Comparison of serum lipid and lipoproteins between patients with and without polyp recurrence

\begin{tabular}{|c|c|c|c|c|c|c|c|c|}
\hline & \multicolumn{2}{|c|}{ Hyperplastic polyp $(n=53)$} & \multicolumn{2}{|c|}{ Inflammatory polyp $(n=33)$} & \multicolumn{2}{|c|}{ Tubular adenoma $(n=285)$} & \multicolumn{2}{|c|}{ Tubulovillous adenoma $(n=64)$} \\
\hline & Recurrent & Nonrecurrent & Recurrent & Nonrecurrent & Recurrent & Nonrecurrent & Recurrent & Nonrecurrent \\
\hline $\mathrm{TG}(\mathrm{mmol} / \mathrm{L})$ & $2.04 \pm 1.48$ & $1.29 \pm 0.71^{*}$ & $1.98 \pm 1.84$ & $1.44 \pm 0.85$ & $1.60 \pm 1.04$ & $1.50 \pm 0.97$ & $1.91 \pm 1.44$ & $1.24 \pm 0.82^{*}$ \\
\hline $\mathrm{CHO}(\mathrm{mmol} / \mathrm{L})$ & $5.64 \pm 1.19$ & $5.52 \pm 1.53$ & $5.23 \pm 0.81$ & $4.85 \pm 1.26$ & $5.31 \pm 1.18$ & $5.39 \pm 1.05$ & $5.73 \pm 1.44$ & $5.72 \pm 0.98$ \\
\hline $\mathrm{HDL}-\mathrm{C}(\mathrm{mmol} / \mathrm{L})$ & $1.28 \pm 0.35$ & $1.45 \pm 0.34$ & $1.30 \pm 0.34$ & $1.42 \pm 0.42$ & $1.36 \pm 0.33$ & $1.40 \pm 0.36$ & $1.26 \pm 0.32$ & $1.50 \pm 0.48^{*}$ \\
\hline LDL-C (mmol/L) & $3.20 \pm 0.89$ & $3.10 \pm 1.02$ & $3.00 \pm 0.61$ & $2.66 \pm 0.87$ & $3.06 \pm 0.81$ & $3.10 \pm 0.79$ & $3.29 \pm 0.98$ & $3.26 \pm 0.72$ \\
\hline ApoA1 (g/L) & $1.24 \pm 0.47$ & $1.41 \pm 0.39$ & $1.33 \pm 0.42$ & $1.32 \pm 0.29$ & $1.31 \pm 0.29$ & $1.35 \pm 0.41$ & $1.23 \pm 0.32$ & $1.45 \pm 0.36^{*}$ \\
\hline ApoB (g/L) & $1.00 \pm 0.31$ & $0.96 \pm 0.31$ & $1.00 \pm 0.28$ & $0.80 \pm 0.25$ & $0.93 \pm 0.24$ & $0.97 \pm 0.27$ & $1.05 \pm 0.34$ & $0.97 \pm 0.25$ \\
\hline TG/HDL & $1.74 \pm 1.64$ & $0.96 \pm 0.74^{*}$ & $1.75 \pm 1.90$ & $1.16 \pm 0.93$ & $1.36 \pm 1.19$ & $1.23 \pm 1.07$ & $1.60 \pm 1.55$ & $0.93 \pm 0.81^{*}$ \\
\hline
\end{tabular}

*: $P<0.05$, comparison between recurrent and nonrecurrent performed by Student's $t$ test 
Table 4 Multivariate analysis of risk factors associated with polyp recurrence

\begin{tabular}{|c|c|c|c|c|}
\hline \multirow[t]{2}{*}{ Parameter } & \multicolumn{2}{|c|}{ All polyps $(n=435)$} & \multicolumn{2}{|c|}{ Advanced adenomas $(n=150)$} \\
\hline & OR $(95 \% \mathrm{Cl})$ & $P$-value & OR $(95 \% \mathrm{Cl})$ & $P$-value \\
\hline Age (years) & $1.02(1.00-1.04)$ & 0.063 & $1.02(0.99-1.06)$ & 0.231 \\
\hline Male & $1.75(1.06-2.89)$ & 0.029 & $0.94(0.41-2.16)$ & 0.891 \\
\hline BMI $\left(\geq 25 \mathrm{~kg} / \mathrm{m}^{2}\right)$ & $1.11(1.02-1.19)$ & 0.012 & $0.96(0.84-1.09)$ & 0.501 \\
\hline Number ( $\geq 3$ ) & $3.42(2.15-5.45)$ & $<0.001$ & $3.28(1.44-7.47)$ & 0.005 \\
\hline Size $(\geq 20 \mathrm{~mm})$ & $1.72(0.87-3.40)$ & 0.117 & $2.86(1.24-6.61)$ & 0.014 \\
\hline $\mathrm{TG}(\geq 1.7 \mathrm{mmol} / \mathrm{L})$ & $1.15(0.90-1.48)$ & 0.257 & $1.55(1.02-2.35)$ & 0.039 \\
\hline $\mathrm{HDL}-\mathrm{C}(\leq 1.04 \mathrm{mmol} / \mathrm{L})$ & $1.47(0.50-4.31)$ & 0.481 & $0.73(0.11-4.70)$ & 0.737 \\
\hline ApoA1 $(<1.0 \mathrm{~g} / \mathrm{L})$ & $0.62(0.25-1.58)$ & 0.318 & $0.364(0.06-2.40)$ & 0.294 \\
\hline
\end{tabular}

OR odd ratio, $C l$ confidence interval, $B M I$ body mass index, $T G$ triglyceride, $H D L-C$ high-density lipoprotein cholesterol, ApoA1 apoliprotein A1

studies have suggested that obesity is a risk factor for colorectal adenomas [31] and CRC mortality [32]. Several studies have determined that obese individuals (or those with a high BMI) have a higher risk of recurrence than non-obese individuals; the underlying mechanism is considered to be the fact that obesity increases the insulin and IGF-1 levels, pushing non-advanced colorectal polyps into the advanced stage and causing recurrence $[12,33,34]$. Consistent with previous findings, we observed that patients with recurrent polyps had a higher $\mathrm{BMI}$, suggesting that the BMI is an independent risk factor for polyp recurrence.

Several studies have investigated the influence of lipid profiles on the development of colorectal polyps. Most of these studies suggested that a higher serum TG level was significantly associated with an increased risk of colorectal adenomas, while a higher HDL level was inversely associated with the development of adenomas [35-39]. Obesity causes oxidative stress and inflammation, resulting in lipid accumulation within organs, which is known to cause insulin resistance and hyperglycemia. Hepatic insulin resistance results in increased TG synthesis and gluconeogenesis, leading to serum hypertriglyceridemia, hypertension, and hyperglycemia [40]. In the current study, we compared the baseline lipid profiles between patients with and without recurrent polyps. The data showed that patients with recurrence had significantly higher TG levels and lower HDL-C and ApoA1 levels. The multivariate logistic regression analysis suggested that an elevated TG level was an independent risk factor for polyp recurrence in patients with advanced adenomas. However, the molecular mechanism by which lipids regulate polyp recurrence remains poorly understood.

Two possible mechanisms may contribute to this phenomenon. First, hypertriglyceridemia is associated with hyperinsulinemia and insulin resistance, which drive cell proliferation via receptors on normal cells and cancer cells of the large bowel [41]. Second, hypertriglyceridemia induces the release of more inflammatory cytokines such as interleukin 6 and tumor necrosis factor alpha and reduces the release of anti-inflammatory cytokines such as interleukin 10 [42, 43], which may create a cellular environment conducive to neoplasia. Studies have suggested that cancer stem cells (CSCs) are responsible for cancer recurrence [44, 45]. Recent studies have shown that lipid droplet-enriched CSCs had higher tumorigenic potential and that lipid droplet accumulation in CSCs contributed to polyp development [46, 47]. We speculate that TG influences polyp recurrence through CSCs by perhaps increasing their proliferation capability or stimulating signaling pathways that promote cell invasion. Further experimental evidence is needed to prove this theory.

\section{Study strengths and limitations}

Researchers have largely focused on risk factors for colorectal polyp recurrence and have identified some baseline colonoscopy features. However, whether lipid abnormalities contribute to colorectal polyp recurrence remains poorly understood. The present study suggests that an elevated TG level is an independent risk factor for recurrence in patients with advanced adenoma, which can be regarded as the main strength of the present study.

This study also has some limitations. First, the retrospective design of the study made it impossible to confirm the accuracy of the self-reported data, such as the BMI and drinking and smoking habits, therefore causing possibly misleading results. Second, the 1.5-year followup may not have been long enough to observe all instances of recurrence, which may be another confounding factor in the data analysis. Third, the molecular mechanism remains unclear, and experimental evidence is needed to strengthen the link between an elevated TG level and polyp recurrence.

\section{Conclusions}

The present study investigated the correlation between lipid profiles and recurrence of colorectal polyps. After 
adjusting for age, sex, BMI, and polyp number and size, the multivariate analysis suggested that an elevated TG level was an independent risk factor for polyp recurrence in patients with advanced adenomas. Because the serum TG level is extensively examined in clinical practice, it may serve as practical marker for defining patients at high risk of polyp recurrence, and helps to protect against CRC.

\section{Abbreviations}

CRC: Colorectal cancer; WHO: World Health Organization; EMR: Endoscopic mucosal resection; TC: Total cholesterol; TG: Triglycerides; HDL-C: Highdensity lipoprotein cholesterol; LDL-C: Low-density lipoprotein cholesterol; ApoA1: Apoliprotein A1; ApoB: Apoliprotein B; BMl: Body mass index; DM: Diabetes mellitus; OR: Odd ratio; Cl: Confidence index

\section{Acknowledgements}

The authors would like to thank doctors in Department of Gastroenterology for the help to this research. The authors also thank Liwen Bianji, Edanz Group China (www.liwenbianji.cn/ac), for editing the English text of a draft of this manuscript.

\section{Authors' contributions}

Sudong Liu conceived the design and wrote the draft; Boying Liu reviewed pathology reports and medical records, chose eligible patients; Pinwu Wen collected clinical data; Xiaodong Gu and Ruiqiang Weng analyzed data. The author(s) read and approved the final manuscript.

\section{Funding}

This study was supported by Fund of Guangdong Provincial Key Laboratory of Precision Medicine and Clinical Translational Research of Hakka Population (2018B030322003)

\section{Availability of data and materials}

The datasets used and analyzed during the current study will be provided by the corresponding author upon reasonable request.

\section{Ethics approval and consent to participate}

The study was approved by the Ethics Committee of Meizhou People's Hospital Affiliated to Sun Yat-Sen University (Ethical Approval Number: MPHHEC 2017-A-28). Informed consent for involvement in the study was obtained from each participant.

\section{Consent for publication}

Not applicable.

\section{Competing interests}

The authors declare that they have no competing interests.

\section{Author details}

'Department of Gastroenterology, Meizhou People's Hospital (Huangtang Hospital), Meizhou Hospital Affiliated to Sun Yat-sen University, No. 63 Huangtang Road, Meijiang District, Meizhou 514031, P. R. China. ${ }^{2}$ Research Experimental Center, Meizhou People's Hospital (Huangtang Hospital), Meizhou Hospital Affiliated to Sun Yat-sen University, No. 63 Huangtang Road, Meijiang District, Meizhou 514031, P. R. China. ${ }^{3}$ Guangdong Provincial Key Laboratory of Precision Medicine and Clinical Translational Research of Hakka Population, No. 63 Huangtang Road, Meijiang District, Meizhou 514031, P. R. China.

Received: 17 July 2020 Accepted: 15 September 2020 Published online: 23 September 2020

\section{References}

1. Siegel RL, Miller KD, Goding Sauer A, Fedewa SA, Butterly LF, Anderson JC, Cercek A, Smith RA, Jemal A. Colorectal cancer statistics, 2020. CA Cancer Clin. 2020;70:145-64

2. Bray F, Ferlay J, Soerjomataram I, Siegel RL, Torre LA, Jemal A. Global cancer statistics 2018: GLOBOCAN estimates of incidence and mortality worldwide for 36 cancers in 185 countries. CA Cancer J Clin. 2018;68:394-424.
3. Zauber AG, Winawer SJ, O'Brien MJ, Lansdorp-Vogelaar I, van Ballegooijen M, Hankey BF, Shi W, Bond JH, Schapiro M, Panish JF, et al. Colonoscopic polypectomy and long-term prevention of colorectal-cancer deaths. N Engl J Med. 2012:366:687-96.

4. Martinez ME, Sampliner R, Marshall JR, Bhattacharyya AK, Reid ME, Alberts DS. Adenoma characteristics as risk factors for recurrence of advanced adenomas. Gastroenterology. 2001;120:1077-83.

5. Mannath J, Subramanian V, Singh R, Telakis E, Ragunath K. Polyp recurrence after endoscopic mucosal resection of sessile and flat colonic adenomas. Dig Dis Sci. 2011;56:2389-95.

6. Hennink SD, van der Meulen-de Jong AE, Wolterbeek R, Crobach AS, Becx MC, Crobach WF, van Haastert M, Ten Hove WR, Kleibeuker JH, Meijssen MA et al. Randomized comparison of surveillance intervals in familial colorectal Cancer. J Clin Oncol. 2015;33:4188-93.

7. Strum WB. Colorectal Adenomas. N Engl J Med. 2016;374:1065-75.

8. Atkin WS, Valori R, Kuipers EJ, Hoff G, Senore C, Segnan N, Jover R, Schmiegel W, Lambert R, Pox C, International Agency for Research on C. European guidelines for quality assurance in colorectal cancer screening and diagnosis. First Edition--Colonoscopic surveillance following adenoma removal. Endoscopy. 2012;44(Suppl 3):SE151-63.

9. Hao Y, Wang Y, Qi M, He X, Zhu Y, Hong J. Risk factors for recurrent colorectal polyps. Gut Liver. 2019;14:399-411.

10. Bardou M, Barkun AN, Martel M. Obesity and colorectal cancer. Gut. 2013;62: 933-47.

11. Jung YS, Park JH, Park DI, Sohn Cl, Choi K. Weight change and obesity are associated with a risk of adenoma recurrence. Dig Dis Sci. 2016;61:2694-703.

12. Jacobs ET, Martinez ME, Alberts DS, Jiang R, Lance P, Lowe KA, Thompson PA. Association between body size and colorectal adenoma recurrence. Clin Gastroenterol Hepatol. 2007;5:982-90.

13. Gunter MJ, Hoover DR, Yu H, Wassertheil-Smoller S, Rohan TE, Manson JE, Howard BV, Wylie-Rosett J, Anderson GL, Ho GY, et al. Insulin, insulin-like growth factor-l, endogenous estradiol, and risk of colorectal cancer in postmenopausal women. Cancer Res. 2008;68:329-37.

14. Kim MC, Jung SW, Kim CS, Chung TH, Yoo Cl, Park NH. Metabolic syndrome is associated with increased risk of recurrent colorectal adenomas in Korean men. Int J Obes. 2012;36:1007-11.

15. Taniguchi L, Higurashi T, Uchiyama T, Kondo Y, Uchida E, Uchiyama S, Jono F, Hamanaka J, Kuriyama H, Hata Y, et al. Metabolic factors accelerate colorectal adenoma recurrence. BMC Gastroenterol. 2014;14:187.

16. Tabuchi M, Kitayama J, Nagawa H. Hypertriglyceridemia is positively correlated with the development of colorectal tubular adenoma in Japanese men. World J Gastroenterol. 2006;12:1261-4.

17. Mutoh M, Akasu T, Takahashi M, Niho N, Yoshida T, Sugimura T, Wakabayashi K. Possible involvement of hyperlipidemia in increasing risk of colorectal tumor development in human familial adenomatous polyposis. Jpn J Clin Oncol. 2006;36:166-71.

18. Chung YW, Han DS, Park YK, Son BK, Paik CH, Lee HL, Jeon YC, Sohn JH. Association of obesity, serum glucose and lipids with the risk of advanced colorectal adenoma and cancer: a case-control study in Korea. Dig Liver Dis. 2006;38:668-72.

19. Kono S, Ikeda N, Yanai F, Yamamoto M, Shigematsu T. Serum lipids and colorectal adenoma among male self-defence officials in northern Kyushu, Japan. Int J Epidemiol. 1990;19:274-8.

20. Xie C, Wen P, Su J, Li Q, Ren Y, Liu Y, Shen R, Ren J. Elevated serum triglyceride and low-density lipoprotein cholesterol promotes the formation of colorectal polyps. BMC Gastroenterol. 2019;19:195.

21. Keku TO, Lund PK, Galanko J, Simmons JG, Woosley JT, Sandler RS. Insulin resistance, apoptosis, and colorectal adenoma risk. Cancer Epidemiol Biomark Prev. 2005:14:2076-81.

22. Meance S, Boutron-Ruault MC, Myara A, Gerhardt MF, Marteau P, Lavergne A, Franchisseur C, Bouley C, Danpolyp Study G. Fecal primary bile acids and serum cholesterol are associated with colorectal adenomas. Dig Dis Sci. 2003:48:1751-7.

23. Huang KW, Leu HB, Wang YJ, Luo JC, Lin HC, Lee FY, Chan WL, Lin JK Chang FY. Patients with nonalcoholic fatty liver disease have higher risk of colorectal adenoma after negative baseline colonoscopy. Color Dis. 2013;15: 830-5.

24. Huang Y, Gong W, Su B, Zhi F, Liu S, Bai Y, Jiang B. Recurrence and surveillance of colorectal adenoma after polypectomy in a southern Chinese population. J Gastroenterol. 2010;45:838-45. 
25. American Diabetes A. Executive summary: standards of medical care in diabetes--2014. Diabetes Care. 2014;37(Suppl 1):S5-13.

26. Alberts DS, Martinez ME, Roe DJ, Guillen-Rodriguez JM, Marshall JR, van Leeuwen JB, Reid ME, Ritenbaugh C, Vargas PA, Bhattacharyya AB, et al. Lack of effect of a high-fiber cereal supplement on the recurrence of colorectal adenomas. Phoenix Colon Cancer prevention Physicians' network. N Engl J Med. 2000;342:1156-62.

27. De Maio G, Zama E, Rengucci C, Calistri D. What influences preneoplastic colorectal lesion recurrence? Oncotarget. 2017;8:12406-16.

28. Lofano K, Principi M, Scavo MP, Pricci M, lerardi E, Di Leo A. Dietary lifestyle and colorectal cancer onset, recurrence, and survival: myth or reality? J Gastrointest Cancer. 2013;44:1-11.

29. Dumoulin FL, Hildenbrand R. Endoscopic resection techniques for colorectal neoplasia: current developments. World J Gastroenterol. 2019; 25:300-7.

30. Wang Y, Zhang FC, Wang YJ. The efficacy and safety of non-steroidal antiinflammatory drugs in preventing the recurrence of colorectal adenoma: a meta-analysis and systematic review of randomized trials. Color Dis. 2015;17: 188-96.

31. Larsen IK, Grotmol T, Almendingen K, Hoff G. Lifestyle as a predictor for colonic neoplasia in asymptomatic individuals. BMC Gastroenterol. 2006;6:5.

32. Haydon AM, Macinnis RJ, English DR, Giles GG. Effect of physical activity and body size on survival after diagnosis with colorectal cancer. Gut. 2006;55:627.

33. Jacobs ET, Ahnen DJ, Ashbeck EL, Baron JA, Greenberg ER, Lance $P$, Lieberman DA, McKeown-Eyssen G, Schatzkin A, Thompson PA, Martinez ME. Association between body mass index and colorectal neoplasia at follow-up colonoscopy: a pooling study. Am J Epidemiol. 2009;169:657-66.

34. Yamaji Y, Okamoto M, Yoshida H, Kawabe T, Wada R, Mitsushima T, Omata $M$. The effect of body weight reduction on the incidence of colorectal adenoma. Am J Gastroenterol. 2008;103:2061-7.

35. Yang MH, Rampal S, Sung J, Choi YH, Son HJ, Lee JH, Kim YH, Chang DK, Rhee PL, Kim JJ, et al. The association of serum lipids with colorectal adenomas. Am J Gastroenterol. 2013;108:833-41.

36. Misciagna G, De Michele G, Guerra V, Cisternino AM, Di Leo A, Freudenheim $J$, Group I. Serum fructosamine and colorectal adenomas. Eur J Epidemiol. 2004:19:425-32

37. van Duijnhoven FJ, Bueno-De-Mesquita HB, Calligaro M, Jenab M, Pischon T, Jansen EH, Frohlich J, Ayyobi A, Overvad K, Toft-Petersen AP, et al. Blood lipid and lipoprotein concentrations and colorectal cancer risk in the European prospective investigation into Cancer and nutrition. Gut. 2011;60: 1094-102.

38. Stocks T, Lukanova A, Bjorge T, Ulmer H, Manjer J, Almquist M, Concin H, Engeland A, Hallmans G, Nagel G, et al. Metabolic factors and the risk of colorectal cancer in 580,000 men and women in the metabolic syndrome and cancer project (me-can). Cancer. 2011;117:2398-407.

39. Suchanek S, Grega T, Ngo O, Vojtechova G, Majek O, Minarikova P, Brogyuk $\mathrm{N}$, Bunganic B, Seifert B, Dusek L, Zavoral M. How significant is the association between metabolic syndrome and prevalence of colorectal neoplasia? World J Gastroenterol. 2016;22:8103-11.

40. Samuel VT, Shulman Gl. The pathogenesis of insulin resistance: integrating signaling pathways and substrate flux. J Clin Invest. 2016;126:12-22.

41. Burchfiel CM, Abbott RD, Curb JD, Sharp DS, Rodriguez BL, Arakaki R, Yano K. Association of insulin levels with lipids and lipoproteins in elderly Japanese-American men. Ann Epidemiol. 1998;8:92-8.

42. Esteve E, Ricart W, Fernandez-Real JM. Dyslipidemia and inflammation: an evolutionary conserved mechanism. Clin Nutr. 2005;24:16-31.

43. Kim NH, Suh JY, Park JH, Park DI, Cho YK, Sohn Cl, Choi K, Jung YS. Parameters of glucose and lipid metabolism affect the occurrence of colorectal adenomas detected by surveillance colonoscopies. Yonsei Med J. 2017;58:347-54

44. Wang D, Fu L, Sun H, Guo L, DuBois RN. Prostaglandin E2 promotes colorectal Cancer stem cell expansion and metastasis in mice. Gastroenterology. 2015;149:1884-95 e1884.

45. Ricci-Vitiani L, Lombardi DG, Pilozzi E, Biffoni M, Todaro M, Peschle C, De Maria R. Identification and expansion of human colon-cancer-initiating cells. Nature. 2007:445:111-5.

46. Tirinato L, Liberale C, Di Franco S, Candeloro P, Benfante A, La Rocca R, Potze L, Marotta R, Ruffilli R, Rajamanickam VP, et al. Lipid droplets: a new player in colorectal cancer stem cells unveiled by spectroscopic imaging. Stem Cells. 2015;33:35-44.

47. Mutoh M, Komiya M, Teraoka N, Ueno T, Takahashi M, Kitahashi T, Sugimura T, Wakabayashi K. Overexpression of low-density lipoprotein receptor and lipid accumulation in intestinal polyps in min mice. Int J Cancer. 2009;125: 2505-10.

\section{Publisher's Note}

Springer Nature remains neutral with regard to jurisdictional claims in published maps and institutional affiliations.
Ready to submit your research? Choose BMC and benefit from:

- fast, convenient online submission

- thorough peer review by experienced researchers in your field

- rapid publication on acceptance

- support for research data, including large and complex data types

- gold Open Access which fosters wider collaboration and increased citations

- maximum visibility for your research: over $100 \mathrm{M}$ website views per year

At BMC, research is always in progress.

Learn more biomedcentral.com/submissions 